\title{
DELIBERATING BEYOND EVIDENCE: LESSONS FROM INTEGRATED ASSESSMENT MODELLING
}

\author{
Elisa Vecchione* \\ Sustainable Development Centre, Sciences Po, Paris \\ elisa.vecchione@sciences-po.org
}

Paper prepared for the Berlin Conference on the Human Dimensions of Global Environmental Change, Evidence for Sustainable Development, 5-6 October, 2012, Berlin.

\begin{abstract}
The premises of this paper rely on associating policy inertia toward action on climate change with the inadequacy of the classical 'liability culture' of evidence-based policy-making to deal with this global environmental challenge. To provide support to this hypothesis, the following discussion analyses the technical properties and the current policy use of Integrated Assessment Modelling (IAM) of economic-climate interactions. The paper contends that IAM is still not clarified enough as far as its potential for information-production in the framework of policy making processes is concerned, and that this fact is symptomatic of the current inability of societies to undertake the challenge of sustainability. The paper explains the reasons for this disconnect and proposes solutions in the form of a renovated framework of deliberative policy-making.
\end{abstract}

Keywords: Integrated Assessment Modelling, evidence, positioning, deliberation

\footnotetext{
* The author gratefully acknowledges funding from the Seventh Framework Programme of the EC for Research, Technological Development and Demonstration Activities - Project No. 227042, Sustainable RIO. For their comments and support, the author is personally grateful to Claude Henry, Olivier Godard, and Sébastien Treyer.
} 


\section{INTRODUCTION}

The concept of sustainable development has found its way onto the political agendas of almost every nation on the planet due to the concern that 'our common future' is threatened by the inability to fuel economic development that respects and integrates an understanding of its social and environmental dimensions. Failure to do so entails the risk that future generations will be prevented from meeting their own needs, as is pointed out in the widely influential Brundtland Report (World Commission on Environment and Development [WCED], 1987). Implicit in the report's definition of sustainable development as a process that 'meets the needs of the present without compromising the ability of future generations to meet their own needs' is a specific kind of social contract much akin to Edmund Burke's (1790) notion of a partnership 'between those who are living, those who are dead, and those who are to be born'.

For this implicit social contract to be honoured, a comprehensive and integrative approach to decision-making is needed across different scales and times. The three pillars of economic development, social development and environmental protection were to be integrated for the sake of non-disruptive development; the responsibility toward future generations emerged with force as a consequence of their entitlement 'to inherit a planet and cultural resource base at least as good as that of previous generations' (Brown-Weiss, 1989, p. 25). Hence, the need for a long-term vision that would adequately integrate the future into current decision-making.

Important theorizations of adaptive management strategies have been formulated in this sense (Bressers, 2004; Lafferty, 2004; Olsson et al., 2006; Rammel \& van den Bergh, 2003; Steurer \& Martinuzzi, 2007), especially with respect to the integration of uncertainty. In practical terms, however, sustainable development has ultimately reinforced the need for policy control and has thus increasingly relied on informative elements that could reduce or eliminate uncertainty. Following this line of reasoning, the evidence produced by technical scientific skills and professional expertise would serve sustainability objectives by triggering a self-evident and compelling change of direction in our ways of living, while at the same time giving the nod to the old mind-set by confirming the usefulness of policy control.

Despite recurring advocacy for a paradigm shift in our modes of thinking and acting, the demand for ever more 'evidence' (of costs and especially benefits) to justify policy action has never waned-even when this evidence, in the form of expert or scientific information, is impossible to produce. After all, production of evidence serves many purposes: it bolsters policy legitimation, provides elements that help coordinate different actors (be they individuals in interest groups, States, industries, etc.), offers some grounds for justification in case of litigation and serves to guarantee multiple accountability. Yet, what if the global challenges we are facing forced us to abandon this approach to formulating and controlling policy? This paper contends that current decision tools, such as Integrated Assessment Modelling (IAM) for climate change policies, are already sufficiently adapted to meet this challenge and, at the same time, to bring about a paradigm shift. What is currently lacking however is a political understanding of a renewed relationship between policy-making and scientific expertise. Scientific information has long been viewed by policymakers as a prop for justifying policy rather than input for resolving policy issues. However, IAM has destabilized policy expectations for (scientific) justification mainly because it is impossible for IA models to produce 'evidence' of certain 
processes that obey a controllable chain of cause and effect. These processes are indeed complex and lead to far distant effects for which the quest for evidence is of little political interest. Basically, modelling traces the connections between specific assumptions and specific scenarios but lays no claim to being able to make predictions.

The way in which IAM functions, based on scenarios and assumptions, will provide the theoretical framework for discussing the kind of policy renovation suggested by the IAM approach. The purpose of this paper is not to identify the best model, but rather to provide a framework for reflection on how the actual use of IAM in policy making can be evaluated. It also aims to propose modifications to the way they are actually used in order to fully clarify what they can contribute to sustainable development policies. To this end, the analysis will focus solely on the case of climate change, for which IAM is suitably used. This example will serve as a basis for the discussion of two fundamental features of sustainable development: the promotion of intergenerational fairness and the integration of scientific uncertainty. This paper will explain how and why these two issues have conflated into the debate on discounting for climate change policies, and how and why this situation has led policy action on emissions abatement into a dead-end search for evidence-based solutions.

The first part of the paper discusses the singularity of IAM, along with scenario-building as compared to other scientific exercises, in order to highlight the elements of destabilization and 'discomfort' at the interface between scientific expertise and decision-making (section 2). The use of cost-benefit analysis in IAM will serve as a foremost example of the 'discomfort' that arises when IAM modellers attempt to adapt the logic of optimization to the properties of IAM (section 3). Exemplary of this tentative adaptation is the fierce debate on the value of the discount rate, along with the inability to resolve genuine uncertainty, which leads to a focus on intergenerational equity as the only issue that can be effectively addressed. The reasons for this impossibility will be explained in section 4 , where the ethics of welfare optimization will be broken down into a specific paradigm of thinking that corresponds to a liability model (section 4.2.). It will be especially interesting to see how this paradigm fits economic reasoning and policy-making into a sort of mutually reinforcing relationship, such as illusterated by the currently widespread evidence-based approach. Section 4.3. will propose the elements required for such a paradigm shift, whereby liability would give the floor to responsibility, and justification to deliberation. More specifically, emphasis will be laid on the role of assumptions in IAM (section 4.2.2.) in order to demonstrate that the choice of assumptions offers a first opportunity to tackle the issue of uncertainty not only in view of expert considerations, but also more fundamentally according to policy preferences and values. As the paper points out, economists are much more aware of this fact than policymakers: section 4.4. will thus conclude by introducing a few lines of thought for exploring how policy preferences can be explicitly linked up with assumptions adopted by IAM. This would be a crucial step toward the creation of a new epistemic community 'which includes not only scientists, but policymakers and other agents and institutions with compelling interests in global change issues' (Edwards, 1996, p. 150). Section 5 concludes.

\section{INTEGRATED ASSESSMENT MODELLING}

\subsection{A technical introduction}

Integrated Assessment Modelling (IAM) refers to a general category of computer models that aim to describe the interactions between human activities, the atmosphere, and natural ecosystems which 
are relevant to complex issues such as climate change, acid rain, land degradation, water and air quality management, forest and fisheries management and public health (cf. Integrated Assessment Society, http://www.tias-web.info/index.php).

For the purpose of this paper, I will concentrate on models of climate change, which combine two sets of information: one related to natural system behaviours (including oceanography, atmospheric dynamics, volcanology, solar physics, carbon-cycle analysis, radiation calculations, ice sheet modelling, paleoclimatology and atmospheric chemistry), and one related to the socio-economic drivers of greenhouse gas emissions (including inter alia economics, engineering, energy, agriculture, health sciences, epidemiology, ecosystems, water management, coastal processes, fisheries, and coral reef ecology) (Sarofim \& Reilly, 2010). To combine such a vast range of disciplines, some simplification is of course necessary. For a start, the behaviour of natural systems is integrated in the form of outputs (trends, heuristics, unproven or qualitative theories) derived from other modelling exercises, such as Global Climate Models (CGMs) or simpler energy-balance models (Sarofim \& Reilly, 2010). IA models can be easily divided into either qualitative narratives or quantitative models (Nebojsa Nakicenovic et al., 2000): the latter apply to the analysis of the cost and benefits of climate mitigation policies so as to inform on the timing and level of 'optimal' effort, while the former are intended to support policy evaluations and compare social visions for alternative emission paths (Mastrandrea, 2010; Metz, Davidson, Bosch, Dave, \& Meyer, 2007; Raskin, Monks, Ribeiro, van Vuuren, \& Zurek, 2005). The models used by the IPCC for instance, such as IMAGE (Integrated Model to Assess the Greenhouse Effect), are designed to provide responses for climate scenarios and climate impacts in the form of qualitative narratives, and in no way do they address the issue of the optimal emission path that should be pursued. On the other hand, IAMs based on quantitative analysis aim to capture the extent to which social and economic processes may contribute to climate change and the benefits and costs of possible mitigation options.

The typical chain of cause and effect of anthropogenic climate change in an IA model starts with emissions scenarios derived from socio-economic scenarios (population, GDP, energy, agriculture, etc.). These are typically referred to as 'storylines' in the IPCC reports, which set the baseline or reference scenarios of no-climate policy intervention. Emissions scenarios are then converted into projections of atmospheric greenhouse gases and aerosol concentrations, radiative forcing of the climate, effects on regional climate, and climatic effects on global sea level (Moss et al., 2010).

${ }^{1}$ In models of social welfare optimization, such as DICE, FUND, and PAGE, emissions scenarios are linked to economic impacts in the following way: emissions are translated into changes in atmospheric greenhouse concentrations, which are then translated into changes in temperature, which are finally translated into economic damages. Each linkage corresponds to a parameter: the carbon cycle translates emission growth into concentrations; climate sensitivity transforms concentration into surface temperature variation, and finally, into economic damages (Hepburn \& Stern, 2008); the stream of economic damages over time is then transformed into a single or a range of possible monetary values (i.e. expressed in terms of percentage of GDP loss) using an appropriate discount factor. All these parameters are a major source of uncertainty in climate modelling, not only because they are hard to estimate, but especially because they are embedded in a feedback relationship with the model's other variables. For instance, once the temperature reaches a level of

\footnotetext{
${ }^{1}$ Emissions scenarios are not only used to derive climate scenarios; they serve also as input to investigate energy and technological alternatives for reaching a desired level of emissions.
} 
$3-4^{\circ} \mathrm{C}$, there is chance that the Amazon forest will collapse, or that permafrost thawing in Antarctica and Greenland will release methane or that the absorptive capacity of the oceans will decrease. All of these events may weaken the carbon cycle, thus impacting the relation between emission flows and concentration stocks, thereby causing the variations in the temperature, and thus in climate damages.

The first IAM of welfare optimization, dating back to 1979, was Nordhaus' Dynamic Integrated Climate-Economy model (DICE). This couples an energy model to emission projections and $\mathrm{CO}_{2}$ concentrations in the following way: various equations defining the accumulation of carbon in the atmosphere capture earth system behaviour; a climate response to increasing concentrations include a lag to account for the inertial effect of the ocean; and global damages are presented as a function of the global mean surface temperature (Sarofim \& Reilly, 2010). In this model, climate change enters the production function via damage and abatement costs. Emissions are in fact considered as an externality of the production process (i.e. economic growth) causing damages that affect production itself; as such, they must be internalized to estimate their impact on social welfare in terms of equivalent change in consumption (i.e. less production, less consumption). The model chooses the level of emission abatement that maximizes social welfare (Stanton, Ackerman, \& Kartha, 2009). Other models, on the other hand, follow a different approach: instead of integrating carbon emission as an externality of the production function, the PAGE model, designed by Hope and used in the 2006 Stern Review, exogenously sets the amount of carbon emissions that can be used in production (on the basis of one emission scenario, the A2, developed by the IPCC's Special Report on Emission Scenarios, SRES, 2000), and formulates all the deviations in terms of abatement costs and the costs of damages (Stanton et al., 2009). This model does not target the optimal level of emission abatement, but builds upon an expected-utility framework to answer the question of what costs would emerge from different emissions paths.

\subsection{The use of scenarios}

IAM also has specific aspects that are relevant for standard research activities. Each of the three terms in its name reveals one of them: 'assessment' indicates that IAM is not aimed at merely advancing understanding for its own sake but that it seeks to usefully inform decision-makers; 'integrated' means that it does not refer to a single disciplinary field in terms of methodology, area of research, etc., but that it promotes a truly interdisciplinary and comprehensive exercise for those areas directly related to human activity; and the term 'modelling' implies that it involves mathematical computer models whose scientific character relies on the construction of scenarios, rather than on producing facts or proof. The IPCC'S SRES report (Nebojsa Nakicenovic et al., 2000) defines a scenario as a plausible description of how the future might develop, based on a coherent and internally consistent set of assumptions about the key relationships and driving forces of the process under analysis. In this sense, IA models do not claim to be predictive in the traditional sense of extrapolating future trends from natural laws or repeated experiments (Grübler \& Nakicenovic, 2001). They instead aim to provide comparisons of policy scenarios and forecasting of trends (Edwards, 1996).

This way of functioning gives IAM both strengths and weaknesses: on the one hand, once the assumptions have been worked out, the model is able to interrelate many factors simultaneously and 
consistently, and to calculate the consequences of their interactions through simulations; on the other hand, the reliability of projections is clearly constrained by the quality and character of the assumptions and data underlying the model. In this respect, IAM produces outcomes that are doubly uncertain: not only are they scenarios and not predictions grounded on cause-and-effect-type probabilities, but also they strictly depend on the way in which assumptions are selected and modelled (see later section 4.2.2.). Indeed, "IAMs can only provide "answers" that are as good as the assumptions that underlie them and the structural fidelity they exhibit' (Schneider 1997, in Schneider \& Lane 2005, p.63).

The dependence on initial assumptions makes the modelling exercise unstable and leaves it open to repeated contestation, as testified for instance by the discussion over what discount rate should be applied to future benefits from emissions mitigations (see later section 3). This makes the use of scenarios less reassuring than conventional predictions about how the future will unfold. As for climate change, the logic and sequences governing interactions between the various parts of the system are particularly complex and uncertainties dominates both natural and economic systems behaviours. $^{2}$

At first glance, then, the combination of this series of uncertainties (the interaction of different types of knowledge, the selection of initial assumptions and the choice between different methodologies) is certainly somewhat worrying for it has the potential to produce a 'cascade of uncertainties ${ }^{\prime 3}(\mathrm{~S}$. H. Schneider, 2001). But, above all, it is uncomfortable both for experts, who have to resolve them and produce clear results, ${ }^{4}$ and decision-makers, who are supposed to use expert knowledge as a justificatory and legitimacy-improving resource.

If the uncertainty of climate-economics interactions and consequences cannot be reduced to a bundle of possible outcomes with attributable and objective probabilities and if this uncertainty can even multiply, it becomes legitimate to question the usefulness of IAM for policy-making. After all, the usefulness of scientific prediction is essentially about reducing uncertainty as to how the future will unfold in order to afford greater control over future events and inform smarter decisions in the present (Sarewitz \& Pielke, 1999). What's more, the proliferation of IA models with their diverging results (the most famous controversy being that between Nordhaus' and Stern's recommendations on the optimality of cutting greenhouse gases emissions) is perplexing for policy interventions. This is even more the case when such recommendations are elaborated in a context of cooperative policymaking. Undoubtedly, the use of models that are structurally different (i.e. use different methodologies) and based on different parameter distributions (i.e. use different inputs) constitutes a real source of uncertainty, rather than a way of solving it (Dietz, 2011b). If IAM is expected to reduce uncertainty by converging its models and thus place policy-making on a sounder footing, then it is disappointingly unsuited to this purpose.

\footnotetext{
${ }^{2}$ On the one hand, climatologists strive to use the most complete knowledge available to model the Earth's behaviour: they detect anomalies or divergences between what the rules of science would predict given certain raw data and what is actually happening. On the other hand, economists have to cope with the fundamental uncertainty of human behaviour and social preferences over the long run.

${ }^{3}$ Uncertainties in emissions scenarios feed into uncertainties in carbon-cycle modelling, which feed into uncertainties in climate modelling, which in turn drive an even larger range of uncertain climate impacts.

${ }^{4}$ For a very clear, insightful discussion on the role of expertise in policy-making, see Roqueplo (1996), who defines the scientific expert as someone forced to trespass beyond the boundaries of his or her own knowledge.
} 
A telling illustration of this situation is the debate about what discount rate should be used to evaluate the costs and the benefits of curbing current greenhouse gases emissions. Section 3 revisits some selected aspects of the discounting debate in order to bring to light a specific conceptual framework to analyse the situation. This will enable us to identify the problems involved when the framework is applied to the challenges of sustainable development in general and climate change in particular.

\section{COST-BENEFIT ANALYSIS}

\subsection{The discount rate}

To say the very least, there are multiple ways in which existing models of welfare optimization for climate change policies (IAM) can match sustainable development ambitions, namely the treatment of long-term uncertainty for the purposes of intergenerational fairness.

The greatest controversy to emerge from the plurality of IAM outcomes is certainly that concerning the value of the discount rate. To put it simply, the discount rate embodies the idea that the value of goods and services changes over time, not according to the intrinsic value of the goods in question, but according to our relative preference for them and, consequently, to the utility we intertemporally gain from them in terms of consumption. Since consumption (like income) is supposed to have declining marginal utility for individuals (i.e. as our consumption of a good increases, there is a level above which we gain proportionally less utility from it), ${ }^{5}$ the discount rate decreases the value of the future with respect to the present. Hence, in a logical intertemporal allocation of resources, the actualization of future values is fundamental in order to estimate the aggregative costs and benefits of current decisions, and thus to decide between competing options of resource allocation over time. For instance, deciding whether to invest resources in a specific project or in treasury bonds, taking into account the expected net benefits. In the context of climate change, this can involve choosing whether to invest in emissions abatement activities in view of the current costs and expected benefits (i.e. avoided damages) of emissions abatement programmes or, for example, in alternative R\&D programmes that might yield higher revenues in terms of social benefits. Of course, the time perspective of the investment, the assumptions on how regularly past consumption trends may continue into the future, and the consequent uncertainty over the future all play a major role in discounting the value of expected benefits and costs.

In the context of climate change, frequent reference is made to Nordhaus' and Stern's analyses of climate change impacts to illustrate the wide range of discount rate values used, and thus the very different conclusions of their analyses, which in turn leads to very diverse policy recommendations. ${ }^{6}$ Nordhaus (2008) applies a discount rate of $5 \%$ to the flow of future damages stemming from additional greenhouse gases emissions. Assuming no mitigation policy, the resulting discounted cost (or discounted benefit from avoiding emissions) is 8 dollars per ton of emission. Stern (2007), on the other hand, uses a discount rate of $1.4 \%$ and obtains a per ton value of 85 dollars. Evidently, the

\footnotetext{
${ }^{5}$ The reason for having diminishing marginal utility of consumption is that we are supposed to continue consuming increasing units of goods and services: the richer we become, the more we consume, and the faster our marginal utility will decline.

${ }^{6}$ For an enlightening discussion on the plurality of values used for the discount rate, see for instance Cole (2007).
} 
benefit-cost calculation resulting from these two different values would, in the first case, seem to argue for no direct action against climate change, while the second case presses for urgent action.

Conventionally, the divergence between these two results has been attributed to a different approach to calculating the discount rate. The descriptive or positive approach holds that the way to derive social preferences over present and future consumption (i.e. estimating the discount rate) is by looking at the rates of saving and investment. The latter is captured by the market interest rate or the opportunity cost of capital (K.J. Arrow et al., 1996; Beckerman \& Hepburn, 2007) and the discount rate should be equal to it. Otherwise, if the discount rate is lower than the interest rate, people would divert investments away from emissions abatement projects toward more profitable ones. This is the approach adopted by Nordhaus (2007). The second approach is a normative or prescriptive one that chooses the value of the discount rate on the basis of specific ethical considerations about its composing parameters, namely the pure rate of time preference indicating our degree of impatience to consume today rather than tomorrow, ${ }^{7}$ and the elasticity of the marginal utility to consumption indicating the extent to which we prefer to consume today rather than tomorrow on the basis of our income ${ }^{8}$ (Cline, 1999; Cowen, 2007; Dasgupta, 2006; Heal, 1997; Stern, 2007). The prescriptive approach is used by Stern and it is rooted in the assumption that those who make decisions on behalf of society should be responsible (or at least not irresponsible), especially for long-term high-impact problems (Cline 1999).

\subsection{Linking the value of the discount rate to intergenerational equity}

The critiques levelled at both approaches are mainly based on intergenerational equity considerations. If we consider that climate change policies are expected to produce high benefits in the future but high costs in the present, a high discount rate severely mars the chance of mitigation policies passing a cost-benefit test. Discounted benefits would be too low with respect to current costs. As a result, the choice of a high discount rate, which is generally required by a descriptive approach, is deemed to penalize future generations and dismiss equity concerns. At the same time, the prescriptive approach, which as a rule tends towards a lower discount rate, would imply a consumption level for current generations of almost near starvation, since saving and investment rates would be far above current practices (K.J. Arrow, 1999). Equity concerns are still taken on board, but this time with respect to current generations.

This is a simplified framework. And obviously, as is to be expected, the relationship between the approach adopted for the discount rate and the ensuing policy conclusions on intergenerational equity issues is much more complex than the above cursory description. For instance, Weitzman $(1998,2007 a)$ uses a descriptive approach and focuses on the opportunity cost of capital, but finally

\footnotetext{
7This is much akin to the 'veil-of-ignorance' situation, as found in Rawls (1971).

${ }^{8}$ The income-based component is expressed through the growth rate of per-capita consumption $g$, which is exogenously taken. However, salient contributions have been emerging which point up the need to review this factor in light of three considerations: the non-marginality of climate change impacts (Dietz \& Hepburn, 2010); the relative price of environmental goods that are reasonably deemed to affect global GDP value (Guesnerie, Henriet, \& Nicolaï, 2012; Sterner \& Persson, 2007); and a preference to incorporate a measure of capital productivity instead of using income to estimate climate change damages (Stanton et al., 2009).
} 
opts for a risk-free rate of return (i.e. very low one). ${ }^{9}$ Yet, even when a high discount rate is used, there can be positive conclusions as to the net benefits of mitigation policies (Sterner and Persson 2008, Revesz and Shahabian 2010). These are just a few examples but they serve to show that the discount rate-intergenerational equity linkage is highly imperfect. Besides, this linkage has been creating an insurmountable set of contradictions directly stemming from a very imperfect translation of intrapersonal choices of resource allocation (informed by the discount rate) into interpersonal and finally intergenerational choices.

The discount rate is estimated at the social aggregation level and the social utility function is constructed such that it has the same properties as an individual utility function. The standard utility function is generally assumed to be concave, indicating that the incremental utility that an individual derives from one additional unit of consumption is less than proportional. The speed at which marginal utility declines (i.e. the curvature of the utility function) is the elasticity of marginal utility. The shift from intrapersonal to interpersonal choices of consumption - that is, aggregation - occurs when we consider the individual at two different moments of her consumption. By using the rule of marginal utility of consumption, we can split a single individual into a 'poorer' and a 'richer' one according to the level of accumulation she has reached. Indeed, if an additional gain in consumption gives proportionally less utility, this means that the previous marginal gain (corresponding to a lower level of income) was higher than the following gain, and so on continuing in reverse. It is precisely by drawing this line between 'before' and 'after' additional consumption that we set the stage for interpersonal judgments: the poorer time of accumulation corresponds to a poor individual, and the richer time to a rich individual. Now, given that the social agent behaves in the same way as the single agent, we can draw a parallel: as much as the single individual allocates resources over time (i.e., over the 'poorer' and the 'richer' time) according to the marginal utility derived from their consumption, the social representative agent allocates resources among 'poorer' and 'richer' individuals until their marginal utilities (higher for the poorer and lower for the richer) are equalized. This is the purpose of making transfers from individuals with lower marginal utility (rich) to individuals with higher marginal utility (poor).

It is precisely the above reasoning that has spurred the debates on intergenerational equity. Much as we suppose that our future consumption will increase as a measure of our welfare, we assume that global society will become richer in the future. The flip side of this assumption is that we can infer that we are now poorer than we will be, hence that our generation is poorer with respect to future generations. Following the logic that it is optimal to reallocate resources in favour of those individuals that have a higher marginal utility of consumption (i.e. poorer people), the question arises as to why we should transfer resources to future richer generations and, if we do so, how much. These are precisely the questions that optimization models try to answer. Certainly, if we pursue the logic of social welfare maximization, the ethical implications are as follows: since the law of decreasing marginal utility informs us that a consumption loss reduces utility more than an equivalent consumption gain increases utility, ${ }^{10}$ society should thus be willing to sacrifice the consumption of a rich person (with lower marginal utility) to help a poor person (with higher marginal utility) and make a transfer accordingly. The higher the elasticity of marginal utility of the

\footnotetext{
${ }^{9}$ The reason adduced by Weitzman for using a low discount rate is that the damages of climate change might not coordinate with aggregate economic activity (Weitzman, 1998, 2007a).

${ }^{10}$ This also indicates that we are risk-averse.
} 
social agent, the smaller (i.e. the less valuable) the additional unit of its marginal utility, the more the transfer from rich to poor makes sense in the logic of welfare optimization.

Following the imperfect chain of intrapersonal-interpersonal-intergenerational judgments in the reverse order, we incorrectly infer one state from another: from an interpersonal judgment such as 'I am rich, you are poor' we end up producing an intergenerational judgment such as 'you'll be richer, so I am poorer' (Heal, 1997). Second, using interpersonal/intergenerational considerations, we are claiming to infer a value for the future and our aversion to risk. New contradictions flare up even more when we take a serious look at the composition of society and aggregate rich and poor in specific ways). ${ }^{11}$ The countries that would gain the greatest benefit from climate change policies (in terms of avoided costs, as they are the most vulnerable countries) are developing countries, many of which will probably be poorer than the rich countries in the present generations (those that are supposed to bear the costs of climate change policies) (Brekke \& Johansson-Stenman, 2008; Dasgupta, 2006; Schelling, 1995). Given this, the idea hardly holds that poorer earlier generations should not engage in costly climate change actions because future generations will be richer, will have more resources to combat climate change and will gain marginally lower satisfaction from present action: the beneficiaries of mitigation policies will probably still have higher marginal utility, because they will in any event be poorer. ${ }^{12}$

The reason of the contradictions created by the application of the 'earlier poorer-later richer' premise to the actual cost-bearers and actual beneficiaries of climate mitigation policies is that the initial premise is based on a very strict assumption: that any resource transfer is Pareto-optimal, which means that any resource transfer unambiguously improves social welfare because it leaves nobody worse-off. This is possible because, as with the Kaldor-Hicks principle, it is supposed that the losers (i.e. cost-bearers) from a policy change will be compensated by the gainers (i.e. beneficiaries). While the compensation assumption barely holds good in the case of individuals (though is nonetheless seriously addressed in real life through fiscal transfer systems), it is all the more untenable for individuals across different times. ${ }^{13}$ Those who would bear the costs of climate change-be it the rich countries in view of their historical responsibilities ${ }^{14}$ or current generationswould not be the ones to receive the benefits. Neither would they receive any compensation for their effort. Conditional on the assumption of compensation, the logic of optimization spurring intergenerational equity reasoning is in no way suitable for identifying decision-making criteria.

\footnotetext{
${ }^{11}$ The construction of a social utility function is independent of the category of individuals that are aggregated. Indeed, the rule of diminishing marginal utility is valid for any individual, irrespective of their initial level of income. And indeed, the standard social utility function imposes the restriction that the marginal elasticity of income be constant and be the same for all individuals

${ }^{12}$ This argument ties up with the current 'common but differentiated responsibility' paradigm that industrialized countries should shoulder the bulk of emission abatement efforts (principle 7 of the Rio Declaration, 1992); however, whereas this principle is put forward on ethical grounds (i.e. the past responsibility of industrialized countries in increasing the atmospheric concentration of carbon dioxide), the argument I have just presented is based on normative considerations of social welfare optimization, recommending that resources be reallocated until equalization of income is achieved across regions.

${ }^{13}$ On the problem of impractical compensation between generations, see for instance, K.J. Arrow (1999); K.J. Arrow et al. (1996); Beckerman and Hepburn (2007); Cline (1999); Cowen (2007); Kysar (2007); Lind (1999); Rawls (1971); Weitzman (1999).

${ }^{14}$ See supra note 12.
} 


\subsection{Caring about a future that we don't know: problems in treating uncertainty through the discount rate}

The above are just few of the contradictions that abound in the economics of climate change. But the very problem is that they all stem from very valuable reasonings that, according to the standard economic approach, can hardly be dismissed as incorrect. If we keep to the above-described approach to welfare optimization, it seems impossible to identify which model is preferred-be it only temporarily. Clearly, we need a change of approach.

To begin with, we need to be aware that until now we have been focusing on intergenerational equity to infer values about the future instead of treating the future (and uncertainty) to infer intergenerational judgements. The definition of sustainable development is indeed ambiguous in this regard. It includes three aspects: integration of the three pillars of economic development, social development and environmental protection for the sake of non-disruptive development; our responsibility toward future generations so as not to compromise the possibility of their meeting their own needs; and, a less evident concern but consequent to this responsibility, the necessity for a long-term vision in order that current decision-making take adequate account of the future. Welfare maximization principles have enabled the first two aspects to be combined into a mutually supportive relationship whereby the efficient use of resources (both man-made and natural) is a condition for intergenerational equity (see Solow 1974). And indeed, the technical treatment of intergenerational equity has not necessitated a great revolution in welfare economics given that it operates on the same principle of concern for resource allocation over time based on the criterion of welfare maximization. On the other hand, the third aspect relating to uncertainty has proved more problematic and has been absorbed into the realm of welfare economics via the expected utility theory. ${ }^{15}$ Certainly, this has been facilitated because the reasoning behind the practice of discounting, in the context of intertemporal allocation of resources, is that not only are we riskaverse-because we do not know the future-but also that we allocate resources according to some opportunity-cost calculation-because we care about the future (Cowen, 2007). However similar, the two issues are not identical: first, caring about the future is a matter of individual interest (Schelling, 1995) and not of altruism, ${ }^{16}$ although some authors would contest this (Dasgupta, 2006); and second, on the climate change issue, it is very difficult to claim that we care about a far-distant future ${ }^{17}$ the core issue being undoubtedly that we do not know the far-distant future. The problem here is that we are unable to address this issue because it escapes our decision-making logic, which fundamentally relies on a comparative type of reasoning, both at the level of economics and policy. Through comparison we can order preferences and derive the (relative) value of different states. But needless to say, for comparing we need a comparative element: the more certain, the better. Future scenarios are intended as a term of comparison with respect to present policies and their alleged policy relevance is generally gauged according to how close they are to what would effectively occur in the future, hence according to their probabilities. Being able to come up with a reliable future becomes fundamental to make comparisons between the present and the future and undertake decisions accordingly. Decisions are generally in the form of balancing these two states and the discussion about future generations has precisely entered this scheme in which future generations

\footnotetext{
${ }^{15}$ The expected utility theory combines discounting and risk aversion.

${ }^{16}$ Altruism is a separate reason adding to risk aversion and opportunity cost (Cowen 2007).

${ }^{17}$ On the contrary, it is plausible to admit that we care about our offspring and use recursive preferences in making intertemporal choices. See Dasgupta (2006).
} 
represent one side of the balance. ${ }^{18}$ Certainly, by interpreting the 'needs' of future generations to mean that they should have a standard of living no lower than current levels (Dietz, Hepburn, \& Stern, 2008), the Brundtland definition of sustainable development indeed implies that some kind of balance needs to be achieved: the concern is that the current consumption and production patterns might not reflect an efficient allocation of resources across time and might therefore disrupt the (tacit) principle of optimization and income equalization to the detriment of future generations. Present generations should thus bear the responsibility of maintaining this equilibrium intact.

However, this way of framing the debate on sustainable development and climate change does not pave the way to a solution. Despite a tentative manipulation of the discounting logic, ${ }^{19}$ the fact is that we cannot create scenarios in terms of probabilistic beliefs ${ }^{20}$ that serve the purpose of comparison. The type of reasoning that long-distant, complex events require is neither comparative nor counterfactual: it puts the present and the future in connection through the "what if" formula, that is, it evaluates claims which are conditional to certain assumptions-as such, difficult to test-and not to facts. Persevering on a comparative logic not only creates several contradictions, some of which have already been presented, but also reinforces a trade-off interpretation of the relation between present and future generations. The kind of responsibility toward the future evoked in the Brundtland definition seems to have metamorphosed into a responsibility toward current generations to do what is 'strictly just'. If the condition of optimization is that those who are made worse-off by a resource transfer be compensated, then the objective is to avoid exceeding the optimal level of efforts and eventually claiming any compensation in favour of the past being, of course, impossible. The Bruntland definition of sustainable development has somehow been turned on its head with the result that the concern now becomes to what extent we should care about future generations without over-compromising our present.

\section{FROM BALANCING TO POSITIONING: DELIBERATING BEYOND EVIDENCE}

In the section above I referred to some crucial concepts underlying the logic and the ethics of welfare economics, such as balance, optimization, compensation. I also suggested that these three concepts have an interesting capacity to adapt to the idea of sustainable development and their ensuing commitments, namely the commitment toward present generations. But then, what about commitments to future generations? Have these been forgotten?

If so, this should come as no surprise. After all, knowledge or consideration of the future is, in policymaking terms, relevant only to the extent that future events have a stake in the present and are

\footnotetext{
${ }^{18}$ Economists generally feel uneasy with applying discounting to the cost-benefit analysis of far-distant events, but it seems virtually impossible to escape the discounting method and especially the comparison of costs and benefits if we wish to obtain a measure of our willingness to pay for undertaking a given action.

${ }^{19}$ Discounting makes sense if we consider that preference and evaluation parameters would hardly change within a short time horizon. Hence, they can remain valid over the period considered. For longer time horizons, this consideration cannot hold.

${ }^{20}$ See for instance Millner, Dietz, and Heal (2010). These authors contend right from outset in their abstract that 'our knowledge of the impacts of climate policy may not be of sufficient quality to justify probabilistic beliefs', putting into question the use of expected utility theory for IAM.
} 
likely to improve it (Sarewitz \& Pielke, 1999). Also, any improvement should be socially unambiguous, in the sense that it should cause no one to be worse-off. These two issues are key to understanding the way in which current policy-making strives to reassure present society that the future is both knowable and controllable. This implies not only that the future may be used for the benefit of the present but also that there will be no marked discontinuity between the past and the present. In this context, any commitment toward a long-distant future quite simply makes no sense since this future has no stake in the present and contributes nothing likely to give reassurance. Consequently, the only type of information-production deemed relevant is that which is able to produce 'reassuring evidence'. Clearly, this way of going about policy-making cannot take advantage of the type of information produced by scientific tools such as IAM. The outcome is twofold: IAM-based science is wrongly blamed for not coming up with certain conclusions, and the community of researchersboth in economics and climatology-are pushed into pursuing the quest for 'conclusive evidence'. ${ }^{21}$ One way out of this highly unproductive state of affairs would be to refocus attention on the issue of uncertainty rather than that of intergenerational equity for sustainable development and climate change policies.

\subsection{Complexity science: uncomfortable effects}

This section will try to reframe the problem of policy-making under uncertainty. It will reconsider the value of science for policy-making and explain why complexity science, if it is to conserve its utility, requires a transformation of policy-making.

In section 2.2., we have already seen that IAM involves specific scientific properties that deviate from the kind of predictive science considered as useful according to the restrictive view of current policymaking. We should first reflect on why prediction has become so indispensable for legitimizing policy-making.

As Sarewitz and Pielke (1999) effectively point out, the role of prediction in science is not the same as in policy: while the former uses prediction to validate its hypotheses (thus lifting them to the level of theories), the latter should use prediction to pursue the enhancement of social welfare with the best tools available, including science. Thus, in principle, the legitimacy of policy-making does not rely on demonstrating the achievement of certain objectives, but on their pursuance. Yet, the demand for control and validation (interestingly, the French verb 'contrôler' includes the idea of both 'controlling' and 'verifying') has never disappeared, ${ }^{22}$ and elections are generally seen as the moment when this demand proves its worth or not. And even though the legitimacy of policy-making does not originally reside in the validation of results, as is the case for science, it has nonetheless assimilated this way of proceeding. It has canalised its quest for evidence via areas of professional expertise, and in

\footnotetext{
${ }^{21}$ For instance, Schneider underlines the importance of coming up whatever happens with probabilities for each scenario, even if these incorporate many subjective components, otherwise the danger is that policymakers be left without guidance (S. H. Schneider, 2001).

${ }^{22}$ Very interesting is the case reported by Godard (2012) of the French General Plan Committee being asked in 1996 to provide the first climate plan according to the energy perspectives of France for the years 2010 and 2020. Three energy scenarios were produced on the basis of three different hypotheses on the evolution of the French and European society. Instead of using the plurality of these scenarios to compare them, understand their insights and try to find some encompassing robust criteria, policymakers used this plurality to choose the scenario that reassured them the most in terms of emissions stabilization and compatibility with the already established environmental and social goals.
} 
particular scientific expertise as this supposedly has the capacity to anticipate the desired policy outcomes and thus provide an anticipated validation of policy choices.

While the kind of science produced by IAM does not correspond to these policy expectations, it nonetheless retains the typical characteristics of science, although less comfortably so. We can reduce scientific knowledge to its capacity to build sequences of events so as to reconstruct the past, explain the present and project it into the future. For non-complex issues, this ability has proved extremely useful for decision-making because it makes it possible to extract a kind of rationality based on a logic replicating events, regardless of their contingent occurrence. And indeed, the usefulness of science has generally resided in the replicative-hence anticipatory-character of scientific knowledge rather than in its basic capacity to sequence phenomena. This implies that for non-complex issues, we may reasonably have a high degree of confidence when projecting the present into the future by looking at past sequences of events. Extending the past into the future is a reliable exercise and produces a somewhat comfortable effect due to the symmetry of the scientific sequences. Uncertainty emerges, however, when a sequence is not fully understood or is incorrect.

For the behaviour of complex systems, on the other hand, the correctness of the sequencing is not related to the emergence of uncertainty. Uncertainty is linked to the fact that the sequence of events accumulates in a specific and non-replicable way, making it impossible to project the present into the future with the same degree of confidence mentioned above. Complexity science can be thought of as a kind of 'historical science' in which the logic of events can be retraced (Buchanan, 2000). As for history, events are always 'retrodictable', which means that it is always possible to find a posteriori an explanatory sequence. However, they are not predictable because their occurrence is dependent on and specific to the emergent properties of the system involved (Turner, 1997). ${ }^{23}$ No matter how precise and how instructive the sequence of past events may be, it will not allow predictions of the future: its usefulness lies in its capacity to warn us about either the replicability or non-replicability of the past events. Hence, the comfortable effect of symmetry between anticipated justifications (i.e. before the event) and subsequent explanations (i.e. after the event) is lost. This means that complexity science and its modelling cannot serve the purpose of validating policy choices. It can, however, provide elements of justificatory explanation. Here, it is important to clearly separate the notions of validation and justification, as neither automatically implies the other. To provide justification to the public, the idea of a policy of control should be abandoned in favour of a new idea of policy as contingent positioning. To find some fertile ground for this change, I will begin by examining the (problematic) properties of scenario production.

\subsection{The use of scenarios: a compulsory rethinking of policy-making}

The use of scenarios for decision-making is certainly not new. It originated in military planning and was then extended to business organizations for the purpose of strategic planning in the 1960s (Moss et al., 2010; Poux, 2003; Raskin et al., 2005). Scenarios have the property of treating uncertainty by structuring it rather than reducing it: they are in fact meant to elucidate elements of uncertainty deriving from the fact that the final outcome depends on how the specific elements of a system interact among themselves.

\footnotetext{
${ }^{23}$ This fact is also defined as 'hysteresis', indicating that the status of a system at a particular point in time and space depends not only on the state of particular variables but also on how that state was reached. SeeBuchanan (2000).
} 
We should question whether this strategic approach to decision-making, inspired by the use of scenarios, is also appropriate for public policy-making. In terms of 'triggering evidence' and consequently of their justificatory power, scenarios are complicated as they do not provide probabilistic forecasts (Mermet, 2003; Millner et al., 2010; Poux, 2003; Raskin et al., 2005), which substantially impairs their 'task of enlightenment'. And indeed, there are authors who emphasize that, to provide policy guidance, it is paramount to use probabilities and attach them to scenarios (S.H. Schneider, 2001). ${ }^{24}$ At the same time, it is contestable whether scientific expertise is useful in terms of policy resolution (Edwards, 1996). If it is not, we should concentrate on the capacity of science to provide elements of policy justification.

\subsubsection{Science for policy justification: the limits of the liability model}

Policy justification for undertaking certain actions is a matter of injecting rationality into policy decisions. In terms of cost-benefit analysis, this injection occurs by determining the worthiness of pursuing a certain goal. Generally, this worthiness is justified by the existence of some inefficiency in the allocation of resources: if there is a margin for improving their employment, the goal is automatically realigned so as to give these resources greater value. Conversely, if there is no resource waste, there is no justification for reallocating resources. To put it simply, rationality informs us whether the status quo needs to be changed or not. To restore the equilibrium that the policy change may have destabilized, the complementary logic of balancing and compensation (see section 3 ) is brought into play. Should a policy action lead to destabilization, the burden of proof that the policy improvement is indeed worthwhile naturally lies with the 'destabilizing policymaker'. The proof or evidence that should be provided not only demonstrates net benefits, but also involves compensation, since any policy improvement should be socially unambiguous (cf. section 3.2.). It is precisely in this sense that the kind of 'comfort' provided by scientific prediction matches a sort of policy-making conservatism. In a consequentialist logic-which underlies welfare economics-the achievement of a specific goal is what counts to retroactively confirm the rationality of a given decision-making process. In as much as this is true, the realization of net benefit and complementary compensation constitutes the crucial element of justification. Policy justifications thus enter a kind of 'liability model' and crucially need technical skills and professional expertise if they are to materialize (Pellizzoni, 2004; Pellizzoni \& Ylönen, 2008). Without these to guarantee the achievement of a given goal, a policy change is difficult to justify.

As explained throughout section 3.2., this consequentialist logic of optimization, balancing, and compensation falls short of justifying climate change mitigation policies. Rejecting the logic of compensation underpinning cost-benefit analysis, Schelling (1995) and Lind (1999) contend that we should enter a logic of transfer or investment: the idea of compensation makes no sense for policies that produce benefits only in the long run while imposing costs in the short run, since there would be no possibility for future generations to compensate present ones for the costs incurred. This logic of compensation does not even hold in the reverse direction: the present generation cannot compensate future generations by transferring resources that offset the costs of climate change because this would require a long-term commitment from one generation to the other to reinvest

\footnotetext{
${ }^{24}$ Probabilistic studies aim at estimating the probability density function (PDF) for crucial input parameters, which allows an explicit estimate of likelihood to be associated with a range of outcomes (Metz et al., 2007).
} 
each year at the same rate of return (K.J. Arrow et al., 1996; Cline, 1999; Heal, 2007; Kysar, 2007; Lind, 1995, 1999). ${ }^{25}$

Even though this compensation logic turns out to be disappointing, we should still keep in mind the notion of commitment. The reference point however should not be the long term, such as that defined in the Hartwick Rule (1977b), which prescribes that subsequent generations reinvest resource rents for later generations in order to compensate them for natural resources depletion. ${ }^{26}$ Instead, our reference point should simply be the fact that each decision is a commitment to something, or as Lind (1999, p. 175) fittingly states: 'each policy decision positions us to make the next policy decision later'. In this perspective, we need to have a vision of the goal we are pursuing and then try to build a strategy that may need repositioning at some later point. Thus, rather than acting on consequentialist and outcome-driven view of rationality, we would be using a sequentialist approach, whereby we position ourselves and decide whether or not to'[buy] an option to facilitate future action' (Lind, 1999, p. 175). ${ }^{27}$ However, there is still the risk of creating a loop: decisions on which kind of 'future action' should be facilitated may be seen to hinge on scientific or expert findings that policy-making should follow up. I shall now point out one more element in IAMproduced information that could in fact eliminate this risk.

\subsubsection{From a consequentialist to a sequentialist approach: the role of assumptions}

We know that each scenario is dependent on the choice of a number of parameters, generally termed assumptions (cf. section 2.2.). The modelling of an integrated system starts by assuming that some parts of the system will behave in a certain way. This choice is not without contention, since apart from orthodox laws of nature, assumptions can be a matter of convention, of historical extrapolation, of empirical finding or of value judgments. The debate over the discount rate should have made this point clear.

In a statistical exercise, the overriding concern should be that assumptions reflect reality as closely as possible. Otherwise, it would be too easy to falsify or reject a very unrealistic hypothesis and the statistical test would lose all significance (Parkhurst, 2001). ${ }^{28}$ In a modelling exercise, this concern should be reconsidered in the light of the fact that modelling is about giving insights into how the future will unfold, starting from the assumption that some parts of it will unfold in a certain way. Unlike backward-looking exercises such as statistics, computer modelling is purely forward-looking. For instance, the reason for modelling climate change impacts is to establish a correspondence

\footnotetext{
${ }^{25}$ See supra note 13.

${ }^{26}$ The Hartwick Rules prescribe that each generation should made sufficient allowance for the depletion of exhaustible resources and invest rents from natural resource depletion in building up reproducible capital goods. The idea behind this is to accumulate reproducible capital so as to offset the inevitable (and efficient) decline in the stock of resources. In this sense, earlier generations are entitled to produce environmental degradation (by drawing on the stock of exhaustible resources) as long as they are able to add to the stock of reproducible capital (Hartwick, 1977a).

${ }^{27}$ For Lind (1999), this is a very good reason to take action now against climate change: indeed the existence of irreversibilities is one such a variable that should be taken into account in our positioning on the subsequent policy decision.

${ }^{28}$ Statistics is devoted to proving the association between two events by disproof, that is, by falsifying an initial hypothesis of non-association (i.e. null hypothesis). However, the convention of using a null hypothesis should be balanced with realistic concerns of using a reliable null hypothesis.
} 
between present trends and possible scenarios for the future: the production of 'storylines' on the evolution of global population, GDP, energy, agriculture, etc. for the purpose of constructing emission scenarios (see section 2.1.) carry out precisely this exercise. Uncertainty arises not only as a result of data errors and the fact that the exercise endeavours to reduce reality through modelling (statistics does the same by sampling reality); it is also due to the fact that the assumptions themselves already integrate or anticipate ideas about the future based on diverse perspectives. Storylines, for instance, are of four types according to whether we suppose global vs. regional integration and economic vs. environmental/social concerns. The question is, however: who should do the supposing? And, in light of what has been said about the role of assumptions, should supposing be simply a matter of 'best guessing' left to the competence of experts, or should it be also a matter of visioning the future on the basis of value judgments? Welfare economists, in a prescriptive approach to the discount rate, would subscribe to the latter option (see section 3.2.), but most of them make such judgements simply in their capacity as experts. Others, instead, would argue that it is the responsibility of political spheres to furnish some insights on policy preferences and value judgments. This is the message of Fankhauser, Tol, and Pearce (1997) when they say that 'the choice of the welfare function is essentially a political question' (p. 263); Cline (1999) commenting that 'for those who take decisions on behalf of society, it is irresponsible' to adopt a positive rate of return for intergenerational equity issues'; or Sterner and Persson (2008) when they remind us that discounting is an ethical exercise since 'we are not simply observing the market as we do in positive or empirical studies, we are providing arguments for public action' (p. 5).

It is precisely by acknowledging that the choice of assumptions is not of trivial import for the policy choice that attention can be shifted away from an evidence-based liability culture for policy-making toward a culture of deliberation. In this case, the science of modelling would reacquire its political connotation and, above all, policy-making would again be invested with the responsibility of taking action 'beyond evidence'. ${ }^{29}$ This is the sense of positioning and of acknowledging that the choice of assumptions is not merely a technical question, but also indicative of policy preferences and thus policy commitments. As Mermet (2003) contends, 'providing ideas on possible futures is about calling for action on the ground ${ }^{30}$ (p.13). And here we arrive at the core of the problems that I mentioned earlier: the risk of creating a loop. Indeed, the challenge is to produce ideas on possible futures without relying on a validating scientific counterfactual and, instead, to take up a position of deliberation without evidence (as opposed to justification through evidence). Certainly, the greatest paradigm shift brought about by the use of IAM for policy-making is the rethinking of rationality as not being necessarily espoused to evidence; a rationality that is deliberative and strategic, rather than merely justificatory and reassuring. To this end, we should explore the notion of liability in its original sense of responsibility.

\footnotetext{
29 Edwards defines models as 'transportable artifacts which embody and communicate community assumptions, beliefs, and shared data' (1996, p.152-53), contributing to the creation of a new epistemic community 'which includes not only scientists, but policymakers and other agents and institutions with compelling interests in global change issues' (1996, p. 150).

${ }^{30}$ Author's translation, 'Émettre des idées sur les futurs possibles, c'est interpeller la sphère de l'action'.
} 


\subsection{Deliberating beyond evidence}

As mentioned earlier, the non-availability of validating scientific counterfactuals makes the justification of action in terms of rational decision-making more complicated. In the case of complex system behaviour, answering the question 'what would have happened if' is simply not feasible. Neither is it possible to fault certain decisions for irrationality on the grounds that, ex-post, they ultimately failed to match a certain evidentiary outcome. In the case of climate change, this impossibility is due both to issues of practical liability for long-term events and to the complexity of the climate system. In fact, one counterfactual that is constantly to hand is the status quo. But this can only play a role in terms of justificatory action if we have ex-post a comparable future or, in other words, a future that has unfolded in an anticipated, predictive way; a future that, ex-ante, is somehow already evident. This is precisely the case of the 'business as usual' scenario, which is constructed by simply extending the present as it is into the future.

Using the status quo as a counterfactual for deciding on complex events makes no sense unless it is intended to justify policy inaction. It is no coincidence that the debate on climate change action has been injected into the problem of finding the correct discount rate for future damages. ${ }^{31}$ Through discounting, our intention is to make the future comparable to the present, but the reason we can do this it is that we suppose that the future will be similar to the present (in terms of relative values). While this may be reasonable for a thirty-year period, for longer time frames it is not. The timehorizon for policy consequences is so stretched that the projection of past trends into future perspectives seems more an exercise of hazard than one of rationality. Indeed, at the risk of overgeneralizing, almost all the contributions to the cost-benefit analysis debate cited in this paper finally conclude with a sense of discomfort as regards the application of cost-benefit analysis to far-distant events. Some even argue for a generalized precautionary principle for treating climate change impacts, in view of the fact that structural uncertainty should serve as a warning as regards our capacity to predict future events (Beckerman, 2007; Weitzman, 2007b).

If complex decisions cannot rely on a counterfactual, then what justificatory basis is available to them? Again, the liability model can be instructive on this count. Different forms of liability exist according to the kind of proof-or evidentiary burden-that has to be discharged. ${ }^{32}$ Generally speaking, the proof concerns the causation of harm to the victim by a product, and/or the fault of the injurer (i.e. negligence or tortious intent). The case of strict liability envisages that the injurer is liable, hence responsible, for the damage caused to the victim regardless of a finding of fault: in order to request compensation, it is sufficient that the victim proves that he has been damaged by a product placed on the market by the potential injurer. It is unnecessary for her to prove the latter's negligence. Hence, the only way the injurer can justify herself is by discharging a burden of proof, which is a burden of blame, linked to ex-post evidence of non-causation of harm to the victim by the product. It is upon this capacity to discharge the burden of proof that the injurer is held liable or not. However, we should pay attention to the fact that even if the injurer is not found liable, this does not mean that she is not responsible for her products. Quite the contrary. She is responsible in all events and from the outset. In fact, the origin of the strict liability rule lies in the fact that the potential

\footnotetext{
${ }^{31}$ Similarly, Revesz and Livermore (2008) denounce an inappropriate use of cost-benefit analysis, especially regarding the use of discounting for treating intergenerational equity issues: 'The convenient untruth is that discounting is appropriate in the intergenerational context. Through the use of discounting, the failure to act on climate change can be justified in cost-benefit terms' (p.108-109).

${ }^{32}$ Moreover, the typology of liability depends on who is to discharge a given burden. In this context, however, it is not relevant and for this reason will not be discussed here.
} 
injurer has an advantage of information to anticipate potential damages that the other parties involved do not have. Thus, the inconsequentiality of establishing the connection between the wrong-doer and the wrong (i.e. negligence) relies on the fact that the wrong-doer is a priori held responsible for her activity and its potential impacts. Indeed, she is responsible for integrating the costs of potential damages into her economic planning. However, her responsibility is somewhat 'invisible', in the sense that in the case of strict liability it does not matter whether the injurer is able to discharge a burden of duty (i.e. duty of due care) or not. Here, my use of the example of strict liability is specifically intended to show how the liability model as applied to decision-making conveys a specific idea of responsibility related to a burden of blame, and thus very easily veils the notion of responsibility as a moral burden of duty. Instead, agents can be held responsible not only on the basis of ex-post evidence, but also prior to any evidence.

\subsection{Assumptions in action: changing the criteria for rational decision- making}

In section 4.2.2., we established that modelling assumptions are value-laden inasmuch as they indirectly express a form of political positioning in order to achieve a specific goal. In the subsequent section, we went on to dismantle the justificatory supremacy of ex-post evidence and liability so as to open up the possibility for a positioning that provides rational criteria for deliberative policy-making. Now, the objective in this section is to have policy preferences expressed directly and explicitly through the choice of assumptions and according to a positioning logic.

I shall start by recalling that the most commonly used method for deducing social (policy) preferences over a future-and in particular future generations-consists in applying a discount rate to the costs and benefits of policy action. Some authors have nonetheless tried to go beyond the discounting debate and concentrate on other uncertainty issues that are not related to the supposed preferences of future generations. I have already mentioned the positions of Schelling (1995) and Lind (1999), which opened a crack in the dominant logic of balancing, compensation and optimization (see supra section 4.2.1.) in favour of a positioning logic. Here, I wish to present further exemplary arguments that strictly address the problem of envisioning reasonable futures beyond evidence or, in other words, beyond the sole replicability of past patterns of behaviour.

I shall highlight two arguments, without however exhausting the whole discussion on the subject raised. Despite their differences, Weitzman $(1996,1998,1999,2007)$ and Dietz $(2011)^{33}$ both focus on one source of concern for modelling climate policies: the impact that climate damages may have on the economy in terms of its composition and aggregative value. It can be fairly said that they approach their economic modelling by taking the position that climate change might make the future very different from the present. This starting point is of course arbitrary, but it is reliable and reasonable inasmuch as most scientific studies on climate change impacts warn that, although very uncertain, the future will indeed probably be very different (Hansen et al., 2008; Solomon et al., 2007).

\footnotetext{
${ }^{33}$ I choose to refer to just one exemplificative work by Dietz, but most of his contributions are actually coauthored. See for instance, Atkinson et al. (2009); Dietz (2011b); Dietz and Hepburn (2010); Dietz et al. (2008); Millner et al. (2010); Saelen et al. (2008).
} 
Two different lines of study concord with this view. One still focuses on the magnitude of the discount rate, but with a special spotlight on the need to weight uncertainty (Weitzman). The other line addresses the fundamental uncertainties related to climate damages, hence to the form of the damage function in IAM (Dietz): one being climate sensitivity in order to understand how changing atmospheric concentrations of greenhouse gases would affect global temperature since temperature variation enters the damage function; ${ }^{34}$ and the other is the curvature of the damage function (i.e. its power) or, in other words, the potential impact of climate damages on the global economy.

It is not the purpose of this paper to go into an extensive discussion of the different approaches. The aim is rather to present a possible practice for assessing assumptions in terms of their capacity to foreground a concern and, from this starting point, integrate uncertainty over the future. As a baseline and in accordance with most behavioural studies, the concern could be generally sourced from an aversion to losses (Brekke \& Johansson-Stenman, 2008; Kahneman \& Tversky, 2000). This given, assumptions are potentially able to integrate this aversion by matching with certain policy preferences expressing such aversion (for instance, toward unacceptable losses). After all, climate change modelling is already framed to further this type of concern because benefits are computed in the form of avoided damages. However, the concern should not be limited to calculating the marginal impacts that these damages may have on the global economy, and should focus on the unacceptable climate-related damages that policy-making is responsible for avoiding. Hence, which type of uncertainty should carry most weight in decision-making? The choice should not prove too difficult since, at the global level, there exist shared values of committed action to which almost all nations worldwide have subscribed. The 1948 Universal Declaration of Human Rights is just one example that could provide a starting point for choosing among different uncertainties. An a priori responsibility in the form of principled commitments should take precedence over an a posteriori infinite liability safely guarded by factual beliefs. And it is in this sense that there is a need to look at the present-instead of focusing on the future-for the purpose of formulating values, projecting them into the future and taking a position accordingly. ${ }^{35}$

For instance, Weitzman refers to the existence of 'fat tails' in the distribution of future damages, which reflect the probability of catastrophic events (1999). He explains that his focus on low-interestrate (i.e. low discount rate) scenarios is dictated by the fact that, given uncertainty, these are the scenarios likely to weigh the heaviest in the expected difference between benefits and costs from climate change impacts (Weitzman, 1998, 1999, 2007b). The economic reasoning for this position is that in the distant future only the low rate matters, because higher rates result in a discount factor approaching zero and thus become non-relevant.

\footnotetext{
${ }^{34}$ Climate sensitivity is one of the most crucial factors for evaluating climate change impacts. It corresponds to the level of warming we expect at a certain stabilization level for greenhouse gases emissions due to a doubling of carbon dioxide concentrations from pre-industrial levels. The IPCC (2007) concludes that there is a $66-90 \%$ chance that climate sensitivity lies in the range of 2.0 to $4.5^{\circ} \mathrm{C}$, with a best-guess of $3^{\circ} \mathrm{C}$.

${ }^{35}$ Although I use a different reasoning, my position here is similar to that of some authors who denounce the deliberate dismissal of current equity problems on the grounds of future concerns. Beckerman (2007) recalls the importance of human rights; Schelling (1995) the key role of development aid programmes; Sterner and Persson (2007) and Stanton et al. (2009) denounce the use of a double standard to justify concern for intertemporal inequality and spatial inequality not only at a conceptual level (e.g. the discussion over resource transfers under optimization policies is valid when considering present poorer generations but not when considering present poorer populations), but also at a technical level through the use of a welfare weight known as the Negishi weight, which prevents reallocation of resources in modelling exercises (Stanton, 2009).
} 
Based on this example, we can highlight one point that goes beyond pure economic reasoning and involves integrated modelling as a whole: the focus for such modelling should concentrate on detecting not relevant similarities but relevant differences between the past and the present for escaping a wrong extension of the present into the future. Of course, evidence of similarities is much less disturbing for policy (in)action, ${ }^{36}$ but similarities would not be relevant to the type of concern mobilized by scientific studies on climate change. Connected with this point is the fact that information production is intended to support the discharge of some burden of proof and we should question exactly which burden we are talking about. If we consider that 'a catastrophe is theoretically possible because a priori knowledge cannot place sufficiently narrow bounds on overall damages' (Weitzman 2011, executive summary), 'the burden of proof in the economics of climate change is presumptively upon whomever wants to model or conceptualize the expected present discounted utility of feasible trajectories under greenhouse warming without having structural uncertainty tending to matter much more than discounting or pure risk per se. Such a middle-of-thedistribution modeler ${ }^{37}$ needs to explain why the inescapably-fattened tails of the posterior-predictive distribution (for which the fat bad tail represents rare disasters under uncertain structure from an unknown scaling parameter) is not the primary focus of attention and does not play the decisive role in the analysis' (Weitzman 2007, p.19). In the same spirit as the precautionary principle, reversing the burden of proof constitutes the first step in re-emphasizing political responsibility of foresight action; the second, and complementary, step is to select the kind of proof that should be discharged (Vecchione, 2011), not in terms of evidence production of course, but in terms of 'committed scenarios' or, in other words, scenarios that respond to specific concerns. This would constitute not only the starting point for deliberative policy-making, but also a response to the rationality requirement to explain policy choices, thus, allowing decision-makers to be held accountable in a sort of 'reverse engineering' exercise ${ }^{38}$ in which the scenarios enable the policy preferences and values contained in assumptions to be retraced.

A similar position toward uncertainty in climate change scenarios is taken up by Dietz (2011), although with a different approach. In his critique of the US Interagency Working Group's estimation of the social cost of carbon (SCC), ${ }^{39}$ he observes that the studies produced give data points for low temperature changes only and exclude the economic impacts of, for example, $+5^{\circ} \mathrm{Celsius}$ over preindustrial levels-a climate situation that scarcely fits past experience as demonstrated by paleoclimatological models of inter-ice age periods, and our future imaginary. However, scientific warnings (IPCC 2007) indicate that this situation cannot be excluded. Dietz thus proposes to extrapolate and make assumptions about functional forms of the damage function, ${ }^{40}$ despite the almost complete lack of related data. In this sense, the plausibility or reasonableness of assumptions should not be calibrated according to how close they are to reality, but according to the kind of

\footnotetext{
${ }^{36}$ With respect to using the status quo as a counterfactual, see supra section 4.3.

${ }^{37}$ The reference is to those authors that use deterministic models and calculate the present value of climate damages by using their probability distribution mean (expectation).

${ }^{38}$ I thank Claude Henry for giving me this expression. Any possible misuse of it is of course my responsibility.

${ }^{39}$ The Social Cost of Carbon 'is the extra climate change impact that would be caused by the emission of one more ton of CO2 into the atmosphere' (Hope 2010), that is, the extent to which we endanger the situation as we continue to emit rather than cut emissions.

${ }^{40}$ On the shape of the damage function where economic impacts rise in proportion to a power (which power indeed?) of temperature change, see also Stanton et al. (2009).
} 
uncertainty that we decide a priori is relevant to trigger a modelling exercise. ${ }^{41}$ Concentrating on the form of the damage function means supposing that climate change may have non-marginal effects on aggregate consumption and accordingly may change the curvature of the utility function. ${ }^{42}$ Nonmarginal changes due to climate impacts imply that the underlying growth rate of the economy may change and the system may shift from one growth path to another (Dietz \& Hepburn, 2010; Hepburn \& Stern, 2008). This possibility is linked to catastrophic scenarios which are usually due to high climate sensitivity and/or a steep damage function. Dietz suggests specific techniques to take these scenarios into account and integrate uncertainty into IAM, ${ }^{43}$ but he also very astutely reminds us that no technical criteria exist allowing a differentiation of the various models (and thus the choice of one over another). Indeed, they are all given equal weight as they are almost impossible to validate from a scientific point of view (see supra section 3.3.). However, the choice of one model over another does indirectly reveal something about policymakers' preferences, for instance whether or not they are averse to ambiguity. By using a'reverse engineering'exercise similar to that proposed above, Dietz (2011) comments that the kind of SCC estimation made by the US Interagency Working Group on SCC can be traced back to the assumption that the decision-maker is ambiguity-neutral. The judgment goes beyond technical considerations and he very correclty concludes that ultimately 'weighting [models] does not stem from a prior belief that one model is more likely to be correct in its forecast than another. [...]. Rather, the weighting stems from decision-making preferences' (p.10).

\section{CONCLUSIONS}

The premises of this paper rely on associating policy inertia toward climate change action with a generalized 'liability culture' of evidence-based policy-making. The discussion has tried to test this association by focusing on the properties of Integrated Assessment Modelling and on its capacity to provide a useful interface between scientific expertise and decision-making.

From a preliminary analysis of the characteristics of IAM, such as the production of scenarios rather than probabilistic outcomes, it soon became clear that this interface was problematic as it could not provide decision-making with incontestable predictions and serve a generalized quest for 'evidence' to trigger compelling action. As a consequence, it also became clear that science and scientific exercises such as IAM should have been addressed under the logic of policy justification rather than one of policy resolution. Justifying was the policy issue, not deliberating. This entangled situation was illustrated by the interminable debate over the application of cost-benefit analysis to ethical concerns such as intergenerational fairness. As explained, the logic of balancing, along with the need

\footnotetext{
${ }^{41}$ It is in the same spirit that some authors have focused on the form of the damage function and found that the SCC may be very high when the damage function becomes much steeper, despite the fact that a different type of model is used-Ackerman and Stanton (2011) use a DICE model applying a functional form proposed by Weitzman (2010), while Dietz (2011) uses a PAGE model and Hanemann (2008), although adopting a different estimation of the temperature change, uses a low temperature change.

${ }^{42}$ Normally, project evaluations ignore this because they assume that projects are generally small and therefore only marginally relevant.

${ }^{43}$ For instance, he warns against the use of standard discounted cash flow analysis when parameter distribution is calculated using a Monte Carlo analysis. He contends that, rather than running this analysis, calculating the mean of the probability distributions for the climate change damages forecasted in each draw, and then applying an exogenous discount rate to the mean value, it would be more correct to have one discount rate for each simulation draw.
} 
to have counterfactual evidence to help weigh up decisions, dominates both the running of optimization models and what policy-making expects from these same models. However, this logic was demonstrated to be an inappropriate fit for the type of information produced by IAM, and thus for the purpose it is supposed to serve. More specifically, the fact that the two key concerns of sustainable development, namely intergenerational equity and uncertainty, have conflated into the discounting debate demonstrates a serious incapability to genuinely address the problem of uncertainty by disguising it as a caring about future generations.

The use of IAM scenarios is particularly relevant to the integrative epistemic effort evoked by sustainable development. Certainly, the use of IAM to analyse the climate-economy system testifies that it is indeed possible to integrate different disciplines, considerations and systems of behaviour. However, this does not correspond to a reduction of uncertainty in policy outcomes. Rather, IAM is intended to structure uncertainty by giving insights into how the future will unfold starting from the assumption that some parts of it will unfold in a specific way. But, as the paper discussed at length, acknowledgement of this aspect of IAM is not yet forthcoming. The reason advanced to explain this lack is that policy-making is currently grounded in a policy framework of social responsibility that is referred to in this paper as a 'liability model'. This framework is characterized, first, by expectations of control over policy outcomes and, second, by attempts to provide a more comfortable vision of the future. In addition to creating inappropriate expectations and uses of IAM, it also tends to confine the debate about the appropriateness of alternative policies to the circle of 'expert arbiters' - be they economists or scientists-and to exclude the most legitimate arbiters, namely the policymakers. This limitation has given rise to a situation in which not only is it very difficult to discriminate among modelling exercises (although this is possible, all models carry very strict and irrefutable rationales); but also in which typical issues of ethical concern, such as intergenerational equity, are reduced to matters requiring purely technical treatment. If such a framework of policy justification is maintained, the risk is that IAM be used to support policy de-responsibilization. The paper has warned of this situation and proposed a new framework of policy responsibility that could fully apprehend the usefulness of IAM over and beyond the sole purpose of justification. Inspired by the idea that decision-making is fundamentally about taking a position with respect to a benchmark future and accordingly buying an option to facilitate action in that direction (Lind 1999), a positioning logic has emerged that could replace the balancing logic. The immediate consideration was, however, that the former is much less comfortable than the latter, for two reasons: first, it is harder to deliver in terms of policy justification and, second, it requires rehabilitating a concept of responsibility that has somehow become obscured by the liability model. To overcome this problem, the paper reconsidered the role of assumptions in IAM, this being strictly connected to scenario production: given that scenarios are reliable to the extent that they refer to certain assumptions and that these assumptions already include a presumption for a certain future, the kind of future targeted by policy action can a priori be apprehended through the way it connects up with specific assumptions, which themselves reveal specific policy preferences. It is in this sense that policymaking can be held accountable through its positioning despite the non-availability of comforting evidence.

The interdependence between policy objectives and policy positioning on the one hand, and between scenarios and assumptions on the other has never been as relevant and crucial as it is today given the complexity of the problems facing policy-making. This interdependence has two implications: first, it reshapes the science-based contours of research activities by shifting attention away from the production of evidence alone onto the plausibility of the assumptions on which 
evidence (in the form of prospect scenarios) is constructed; secondly, it highlights the fact that the selection of assumptions reveals not only elements of plausible science, but also elements of desirable policy. It is in this sense that the discussion on IAM's properties has the merit of reemphasizing the notion of a political responsibility to act even in the face of deep uncertainties-a type of responsibility already encompassed by the precautionary principle. It also has the merit of bringing to fore-once again-the fact that the division between science and policy, between competency and legitimacy, between facts and value, is untenable, unless used to justify policy inertia. 


\section{REFERENCES}

Ackerman, F., \& Stanton, E. A. (2011). Climate risks and carbon prices: Revising the social cost of carbon: Kiel Institute for the World Economy.

Angeletos, G.-M., Laibson, D., Repetto, A., Tobacman, J., \& Weinberg, S. (2009). The Hyperbolic Consumption Model: Calibration, Simulation, and Empirical Evaluation. In E. L. Khalil (Ed.), The New Behavioral Economics. Volume 2. A Taste for the Present (pp. 215-236): Elgar Reference Collection. International Library of Critical Writings in Economics, vol. 238. Cheltenham, U.K. and Northampton, Mass.: Elgar. (Reprinted from: [2001]).

Arrow, K. J. (1963). Social Choice and Invididual Values (2nd ed.). New Haeven, CT: Yale University Press.

Arrow, K. J. (1999). Discounting, Morality, and Gaming. In P. R. Portney \& J. P. Weyant (Eds.), Discounting and Intergenerational Equity (pp. 13-15). Washington, D.C.: Resources for the Future.

Arrow, K. J., Cline, W. R., \& Mäler, K.-G. (1996). Intertemporal Equity, Discounting, and Economic Efficiency Economic and Social Dimensions of Climate Change. Contribution of Working Group III to the Second Assessment Report of the Intergovernmental Panel on Climate Change (pp. 129-144). Cambridge Cambridge University Press.

Atkinson, G., Dietz, S., Hepburn, C., Helgeson, J., \& Sælen, H. (2009). Siblings, Not Triplets: Social Preferences for Risk, Inequality and Time in Discounting Climate Change. Economics: The Open-Access, Open Assessment E-Journal, 3 (2009-26).

Banuri, T., Göran-Mäler, K., Grubb, M., Jacobson, H. K., \& Yamin, F. (1996). Equity and Social Considerations Climate Change 1995: Economic and Social Dimensions of Climate Change, Contribution of Working Group III to the Second Assessment Report of the IPCC, (pp. 79-124). Cambridge: Cambridge University Press.

Beckerman, W. (2007). The chimera of "sustainable development". The Electronic Journal of Sustainable Development, 1(1), 17-26.

Beckerman, W., \& Hepburn, C. (2007). Ethics of the Discount Rate in the Stern Review on the Economics of Climate Change. World Economics Journal, 8(1), 187-210.

Brekke, K. A., \& Johansson-Stenman, O. (2008). The behavioural economics of climate change. Oxford Review of Economic Policy, 24(2), 280-297. doi: 10.1093/oxrep/grn012

Bressers, H. (2004). Understanding the implementation of instruments: How to know what works, where, when and how. In W. M. Lafferty (Ed.), Governance for Sustainable Development. The Challenge of Adapting Form to Function. Cheltenham, UK; Northampton, MA, USA: Edward Elgar.

Brown-Weiss, E. (1989). Fairness to future generations: international law, common patrimony, and intergenerational equity. Tokyo: Unites Nations University Press.

Buchanan, M. (2000). Ubiquity: The Science of History . . or Why the World Is Simpler Than We Think. London, UK: Weidenfeld \& Nichols.

Cline, W. R. (1999). Discounting for the very long term Discounting and intergenerational equity. Washington, DC: Resources for the Future.

Cole, D. H. (2007). The Stern Review and its critics: implications for the theory and practice of costsbenefits analysis. QA - Rivista dell'Associazione Rossi-Doria (4).

Cowen, T. (2007). Caring about the Distant Future: Why It Matters and What It Means. The University of Chicago Law Review, 74(1), 5-40.

Dasgupta, P. (2006). Comments on the Stern Review's Economics of Climate Change. Paper presented at the Stern Review's Economics of Climate Change, Foundation for Science and Technology, Royal Society, London. 
Dietz, S. (2011a). Comments on "Climate Risks and Carbon Prices: Revising the Social Cost of Carbon". Economics for Equity and the Environment (E3 Network). Retrieved from http://www.e3network.org/papers/Climate Risks and Carbon Prices comments.pdf

Dietz, S. (2011b). The treatment of risk and uncertainty in the US Social Cost of Carbon for Regulatory Impact Analysis. Grantham Research Institute on Climate Change and the Environment Working Paper No. 54. Working Paper. Grantham Research Institute on Climate Change and he Environment London, UK.

Dietz, S., \& Hepburn, C. (2010). On non-marginal cost-benefit analysis. Grantham Research Institute on Climate Change and the Environment Working Paper (No. 18).

Dietz, S., Hepburn, C., \& Stern, N. (2008). Economics, ethics and climate change. SSRN working paper series. Retrieved from

Edwards, P. N. (1996). Global comprehensive models in politics and policy-making. Climatic Change, 32, 149-161.

Fankhauser, S., Tol, R., \& Pearce, D. (1997). The Aggregation of Climate Change Damages: a Welfare Theoretic Approach. Environmental \& Resource Economics, 10(3), 249-266.

Godard, O. (2012). Expertise scientifique d'enjeux collectifs et décision publique. In P.-A. Chardel, C. Gossart \& B. Reber (Eds.), Conflit des interprétations dans la société de l'information. Éthiques et politiques de l'environnement. Paris: Hermès Éditions.

Grübler, A., \& Nakicenovic, N. (2001, July 5, 2001). Identifying dangers in an uncertain climate. Nature, 412, 15.

Guesnerie, R., Henriet, F., \& Nicolaï, J.-P. (2012). Trois questions épineuses à l'arrière-plan des politiques climatiques. In R. Gary-Bobo \& I. Laudier (Eds.), Economie, Environnement et Destin des Générations Futures. Amiens: Annals of Economics and Statistics.

Hanemann, M. (2008). What is the economic cost of climate change? Berkeley, CA,: University of California.

Hansen, J., Sato, M., Kharecha, P., Beerling, D., Berner, R., Masson-Delmotte, V., . . Zachos, J. C. (2008). Target Atmospheric CO2: Where Should Humanity Aim? The Open Atmospheric Science Journal, 2(1), 217-231.

Harrod, R. (1948). Towards a Dynamic Economics. London: Macmillan.

Harsanyi, J. C. (1955). Cardinal welfare, individualistic ethics, and interpersonal comparisons of utility. The Journal of Political Economy, 63(4), 309-321.

Harsanyi, J. C. (1976). Essays on Ethics, Social Behavior, and Scientific Explanation. Dordrecht, Holland: D. Reidel.

Hartwick, J. M. (1977a). Intergenerational Equity and the Investing of Rents from Exhaustible Resources. The American Economic Review, 67(5), 972-974.

Hartwick, J. M. (1977b). Intergenerational equity and the investing of rents from exhaustible resources American Economic Review, 67 (5), 972-974.

Heal, G. (1997). Discounting and climate change. Climatic Change, 37(2), 335-343.

Heal, G. (2007). Discounting: A Review of the Basic Economics. The University of Chicago Law Review, 74(1), 59-77.

Hepburn, C., \& Stern, N. (2008). A new global deal on climate change. Oxford Review of Economic Policy, 24(2), 259-279. doi: 10.1093/oxrep/grn020

Kahneman, D., \& Tversky, A. (2000). Choices, Values, and Frames (1st ed.). New York: Cambridge University Press.

Kysar, D. A. (2007). Discounting ... on Stilts. The University of Chicago Law Review, 74(1), 119-138.

Lafferty, W. M. (2004). Introduction: form and function in governance for sustainable development. In W. M. Lafferty (Ed.), Governance for Sustainable Development. The Challenge of Adapting Form to Function (pp. 1-31). Cheltenham, UK; Northampton, MA, USA: Edward Elgar.

Laibson, D. (2009). Golden Eggs and Hyperbolic Discounting. In E. L. Khalil (Ed.), The New Behavioral Economics. Volume 2. A Taste for the Present (pp. 180-214): Elgar Reference Collection. International Library of Critical Writings in Economics, vol. 238. Cheltenham, U.K. and Northampton, Mass.: Elgar. (Reprinted from: [1997]). 
Lind, R. C. (1995). Intergenerational equity, discounting, and the role of cost-benefit analysis in evaluating global climate policy. Energy Policy, 23(4-5), 379-389.

Lind, R. C. (1999). Analysis for Intergenerational Decisionmaking Discounting and intergenerational equity. Washington, DC: Resources for the Future.

Loewenstein, G., \& Prelec, D. (2000). Anomalies in Intertemporal Choice: Evidence and an Interpretation. In D. Kahneman \& A. Tversky (Eds.), Choices, values, and frames (pp. 578596): Cambridge; New York and Melbourne:Cambridge University Press;New York:Russell Sage Foundation. (Reprinted from: [1992]).

Mastrandrea, M. D. (2010). Representation of Climate Impacts in Integrated Assessment Models. Paper presented at the Assessing the Benefits of Avoided Climate Change: Cost-Benefit Analysis and Beyond, Washington, DC.

Mermet, L. (2003). La prospective dans le demaine de la recherche environmentale: un ensemble de défis à relever. In L. Mermet (Ed.), Prospectives pour l'environnement. Quelles recherches? Quelles ressources? Quelles méthodes? Paris: La Documentation française.

Metz, B., Davidson, O. R., Bosch, P. R., Dave, R., \& Meyer, L. A. (2007). Contribution of Working Group III to the Fourth Assessment Report of the Intergovernmental Panel on Climate Change, 2007. Cambridge, UK; New York, NY, USA: Cambridge University Press.

Millner, A., Dietz, S., \& Heal, G. (2010). Ambiguity and climate policy. National Bureau of Economic Research Working Paper Series, NO. 16050.

Moss, R. H., Edmonds, J. A., Hibbard, K. A., Manning, M. R., Rose, S. K., van Vuuren, D. P., . . . Wilbanks, T. J. (2010). The next generation of scenarios for climate change research and assessment. Nature, 463(7282), 747-756.

Nakicenovic, N., Alcamo, J., Davis, G., de Vries, B., Fenhann, J., Gaffin, S., . . Dadi, Z. (2000). Special Report on Emissions Scenarios : a special report of Working Group III of the Intergovernmental Panel on Climate Change.

Nakicenovic, N., Alcamo, J., Davis, G., de Vries, B., Fenhann, J., Gaffin, S., . . Dadi, Z. (2000). Special Report on Emissions Scenarios: A Special Report of Working Group III of the Intergovernmental Panel on Climate Change. Cambridge, UK: Cambridge University Press.

Nordhaus, W. D. (2007). A Review of the Stern Review on the Economics of Climate. Journal of Economic Literature, 45(3), 686-702.

Nordhaus, W. D. (2008). A Question of Balance: Weighing the Options on Global Warming Policies. New Haven: Yale University Press.

Olsson, P., Gunderson, L. H., Carpenter, S. R., Ryan, P., Lebel, L., Folke, C., \& Holling, C. S. (2006). Shooting the rapids: navigating transitions to adaptive governance of social-ecological systems. Ecology and Society, 11(1), 18.

Parkhurst, D. F. (2001). Statistical Significance Tests: Equivalence and Reverse Tests Should Reduce Misinterpretation. Bioscience, 51(12), 1051.

Pellizzoni, L. (2004). Responsibility and Environmental Governance. Environmental Politics, 13(3), 541-565. doi: 10.1080/0964401042000229034

Pellizzoni, L., \& Ylönen, M. (2008). Responsibility in Uncertain Times: An Institutional Perspective on Precaution. [Article]. Global Environmental Politics, 8(3), 51-73.

Poux, X. (2003). Les méthodes de scénarios. In L. Mermet (Ed.), Prospectives pour l'environnement. Quelles recherches? Quelles ressources? Quelles méthodes? (pp. 33-50). Paris: La Documentation française.

Rammel, C., \& van den Bergh, J. C. J. M. (2003). Evolutionary policies for sustainable development: adaptive flexibility and risk minimising. Ecological Economics, 47, 121-133.

Raskin, P., Monks, F., Ribeiro, T., van Vuuren, D., \& Zurek, M. (2005). Global Scenarios in Historical Perspective. In S. Carpenter, P. Pingali, E. Bennett \& M. Zurek (Eds.), Ecosystems and Human Well-Being: Scenarios - Findings of the Scenarios Working Group Millennium Ecosystem Assessment Series (pp. 35-44). Washington, DC: Island Press.

Rawls, J. (1971). A theory of justice. Cambridge MA: Harvard University Press. 
Revesz, R. L., \& Shahabian, M. R. (2010). Climate Change and Future Generations. PUBLIC LAW \& LEGAL THEORY RESEARCH PAPER SERIES WORKING PAPER NO. 10-59.

Roqueplo, P. (1996). Entre savoir et décision, l'expertise scientifique. Paris: INRA.

Saelen, H., Atkinson, G., Dietz, S., Helgeson, J., \& Hepburn, C. (2008). Risk,inequality and time in the welfare economics of climate change: is the workhorse model underspecified? : University of Oxford, Department of Economics.

Sarewitz, D., \& Pielke, R. (1999). Prediction in science and policy. Technology in Society, 21(2), 121133.

Sarofim, M. C., \& Reilly, J. M. (2010). Applications of integrated assessment modeling to climate change. Wiley Interdisciplinary Reviews: Climate Change, 2(1), 27-44. doi: 10.1002/wcc.93

Schelling, T. C. (1995). Intergenerational discounting. Energy Policy, 23(4-5), 395-401.

Schneider, S., \& Lane, J. (2005). Integrated Assessment Modeling of Global Climate Change: Much has been Learned - Still a Long and Bumpy Road Ahead. The Integrated Assessment Journal, 5(1), 41-75.

Schneider, S. H. (2001). What is 'dangerous' about climate change? Nature, 411, 17-19.

Solomon, S., Qin, D., Manning, M., Chen, Z., Marquis, M., Averyt, K. B., . . Miller, H. L. (2007). Contribution of Working Group I to the Fourth Assessment Report of the Intergovernmental Panel on Climate Change IPCC Fourth Assessment Report: Climate Change 2007 (AR4). Cambridge, United Kingdom; New York, NY, USA: IPCC.

Solow, R. M. (1974). Intergenerational Equity and Exhaustible Resources. The Review of Economic Studies, 41, 29-45.

Solow, R. M. (1986). On the Intergenerational Allocation of Natural Resources. The Scandinavian Journal of Economics, 88(1), 141-149.

Stanton, E. A. (2009). Negishi Welfare Weights: The Mathematics of Global Inequality. Working Paper WP-US-09022.

Stanton, E. A., Ackerman, F., \& Kartha, S. (2009). Inside the integrated assessment models: Four issues in climate economics. Climate and Development, 1(2), 166-184.

Stern, N. (2007). The economics of climate change. The Stern review. Cambridge: Cambridge University Press.

Sterner, T., \& Persson, U. M. (2007). An Even Sterner Review: Introducing Relative Prices into the Discounting Debate. Review of Environmental Economics and Policy, 2(1), 61-76. doi: 10.1093/reep/rem024

Steurer, R., \& Martinuzzi, A. (2007). From environmental plans to sustainable development strategies. European Environment, 17(3), 147-151.

Turner, F. (1997). Chaos and Social Science. In R. A. Eve, S. Horsfall \& M. E. Lee (Eds.), Chaos, complexity, and sociology. Myths, models, and theories (pp. xi-xxv). Unites States of America: SAGE Publications, Inc.

Vecchione, E. (2011). Science for the environment: examining the allocation of the burden of uncertainty. European Journal of Risk Regulation(2), 227-239.

Weitzman, M. L. (1998). Why the Far-Distant Future Should Be Discounted at Its Lowest Possible Rate. Journal of Environmental Economics and Management, 36(3), 201-208.

Weitzman, M. L. (1999). Just keep discounting, but... In P. R. W. Portney, John (Ed.), Discounting and Intergenerational Equity (pp. 23-29). Washington, DC: Resources for the Future.

Weitzman, M. L. (2007a). A Review of the Stern Review on the Economics of Climate Change. Journal of Economic Literature, 45(3), 703-724.

Weitzman, M. L. (2007b). Role of Uncertainty in the Economics of Catastrophic Climate Change. SSRN eLibrary. doi: 10.2139/ssrn.992873

Weitzman, M. L. (2010). GHG Targets as Insurance Against Catastrophic Climate Damages. National Bureau of Economic Research Working Paper Series, No. 16136.

World Commission on Environment and Development (WCED) (1987). Our common future. Oxford: Oxford University Press. 